\title{
Some results of statistical grouping and classification of energy materials on characteristics of thermal decomposition and heat explosion
}

\author{
(C) Vladimir N. Popok \\ Joint Stock Company "Federal Research and Production Center "Altay". \\ Socialistic St., 1. Biysk, 659322. Altay Kray, Russia. \\ Phone:+7 (3854) 30-19-37.E-mail:vnpopok@mail.ru
}

Keywords: Heat explosion, thermal decomposition, mixtures, components, classification, statistical methods of grouping.

\begin{abstract}
Annotation to date has accumulated a large amount of experimental data on the characteristics of thermal decomposition and heat explosion of individual and mixed energy materials. A specific feature of this data is the multidimensional nature-a large number of characteristics and objects, a variety of methods of their definition and description, the availability of qualitative and quantitative characteristics, gaps in data. These results require some processing and systematization in order to obtain reliable empirical or calibration models and methods of describing and predicting the behavior of the materials under external thermal influences. Another task, which is of decisive importance in the practice of using the materials under consideration, is their classification, construction of sensitivity and hazard series, search for analogue and others.

An important role in such processing is given to statistical methods of grouping, allowing to reveal the latent structure of data, to organize their grouping on the basis of objective or research characteristics. Grouping allows to reduce to acceptable values dispersion (square of standard deviation) of results of processing of quantitative data and errors of grouping and classification on qualitative or mixed data. To carry out such work, effective statistical methods and programs are developed that allow processing large data arrays (many objects and characteristics-properties) with visualization of results. These methods include correlation, discriminant, factor analysis, clustering, multidimensional scaling and others.

The use of a priori information allows in some cases to divide the aggregate of results into groups (clustering) on the grounds, for example, compatibility and thermal resistance of components taking into account active functional groups Compounds of different classes, as is done in relation to the use of nanosized powders of metals and their oxides in mixed energy materials. The similar situation is realized also at establishment of correlation ratios between parameters of thermal durability and heat explosion of energy components and mixes at use of a priori information on formation of molecular Complexes and co-crystallizes between components in compositions.

The proposed article presents the results of the application of statistical methods of grouping and classifying individual and mixed energy materials on the basis of analysis of many-dimensional data on their thermal decomposition and thermal explosion.
\end{abstract}

\section{References}

[1] Statistical Methods for Digital Computers Edited by Kurt Enslein, Antony Ralston, Herbert S. Wilf. John Wiley \& Sons. Inc. 1977.

[2] V.N. Popok. Correlation of thermal explosion characteristics and thermal decomposition of components and compositions of mixed energy materials. Butlerov Communications. 2018. Vol.56. No.12. P.71-77. DOI: $10.37952 / R O I-j b c-01 / 18-56-12-71$

[3] V.N. Popok, N.P. Vdovina, N.V. Bychin. Compatibility of nanodispersed powders of metals and their oxides with components of mixed energy materials. Russian nanotechnology. 2013. Vol. 8. No.1-2. P.7783. (russian)

[4] V.N. Popok, V.N. Khmelev. Mixed condensed chemical fuels based on ammonium nitrate. Principles of layout and properties: Monography. Biysk: Izd-vo Altstu. 2014. 222p. (russian)

[5] V.N. Popok. Research on hexanitrohexaazaisowurtzitane/polymer co-crystallizate properties. Butlerov Communications. 2012. Vol.30. No.6. P.132-143. ROI: jbc-02/12-30-6-132

[6] V.N. Popok, G.V. Teplov, and N.I. Popok. Co-crystallizates of benzo-tris-(1,2,5-oxadiazol-2-oxide). Butlerov Communications. 2014. Vol.38. No.5. P.1-12. ROI: jbc-02/14-38-5-1

Kazan. The Republic of Tatarstan. Russia. (C) Butlerov Communications. 2019. Vol.57. No.2. 
[7] J.N. Miller, J.C. Miller. Statistics and chemometrics for analytical chemistry. 6th ed. Essex: Pearson Education. 2010.

[8] P. Saganowska, M. Wesolowski. Principal component and cluster analyses as supporting tools for cocrystals detection. J. Therm. Anal. Calorim. 2017. Vol.130. P.45-55.

[9] D.L. Massart, L. Kaufman. The interpretation of analytical chemical data by the use of cluster analysis. New York: Wiley. 1983.

[10] V.N. Popok, and A.S. Zharkov. Characteristics of thermal decomposition and thermal explosion of certain components of composite energetic materials. Butlerov Communications. 2015. Vol.42. No.6. P.11-16. DOI: 10.37952/ROI-jbc-01/15-42-6-11

[11] V.N. Popok, and K.F. Il'inykh. Thermal explosion of mixed energy materials on the basis of various combustible binders and oxidizers. Butlerov Communications. 2013. Vol.33. No.3. P.42-48. ROI: jbc02/13-33-3-42

[12] V.N. Popok, N.V. Bichin, P.I. Taronov. Features of thermal decomposition and thermal explosion of compositions with polycrystals of polyethylene glycol, cyclic nitrates and oxidizing agents. Butlerov Communications. 2018. Vol.56. No.12. P.60-69. DOI: 10.37952/ROI-jbc-01/18-56-12-60

[13] Q.L. Yan, M. Kunzel, S. Zeman, R. Svoboda, M. Bartoskova. The effect of molecular structure on thermal stability, decomposition kinetics and reaction models of nitric esters. Thermochimica Acta. 2013. Vol.566. P.137-148. 